\title{
Application of Virtual Reality Technology in the Training of Crane Operators
}

\author{
Haoming Dong \\ Wuhan special equipment supervision and Inspection Institute, China
}

\begin{abstract}
This paper introduces the application of the virtual reality to train the operator of crane. Through the new method, we can improve the quality of training and ability of the operator of crane.
\end{abstract}

\section{Keywords_- virtual reality; bridge crane; training}

\section{VIRTUAL REALITY TECHNOLOGY}

Virtual reality (VR) also is known as virtual environment (VE). It uses computer technology as the core of modern high-tech to generate realistic visual, auditory, tactile integration of a specific range of virtual environment. With the necessary equipment, the user can interact with the virtual environment in a natural way. [1]

VR combines the advanced information technology (such as network computing, graphics, image processing, multimedia technology, sensor, simulation, etc.) and even psychology, bionics, arts and other areas of research results. Its purpose is to build an efficient multi-dimensional, more harmonious environment, which can make people immersed in one, virtual reality, and interact with each other. [2]

VR technology is to allow users to immerse in an artificial virtual environment. They can carry on the idea, complete the task through the virtual reality software and the external device and the computer. Its concept is like Figure I

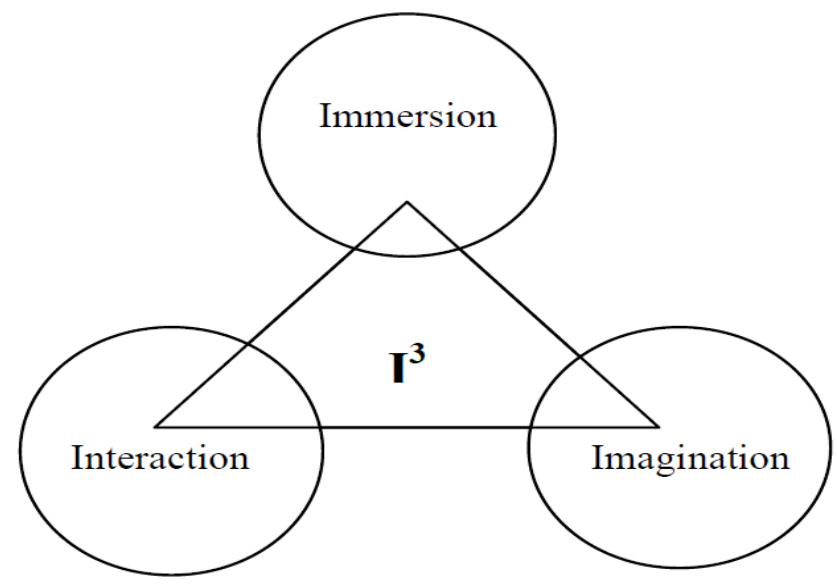

FIGURE I. VIRTUAL REALITY I ${ }^{3}$

\section{ThE STATUS QUO OF THE TRAINING OF CRANE OPERATORS}

In recent years, domestic production safety situation is not optimistic, hoisting and conveying machinery operation accidents occur from time to time. The important reasons include the operators' lack of professional knowledge, skills not skilled, safe operation quality is not high, improper operation and so on.

At present, the crane as the category of special equipment, in our country has established a sound special operation safety training management system, but the training process and the training mode is lagging behind. In the course of training, because the teaching material content is obsolete, the teaching method is backward; the actual operation is subject to the field conditions, resulting in the crane operators did not really learn advanced industry theory knowledge, practical ability is not strong, resulting in poor training effect, leaving a large amount of accident risk.

Therefore, it is an urgent task to change the current situation of the crane operators, improve the professional quality and operation skills of the workers, and ensure the safety and stability of crane. At present, virtual reality technology has been applied in many fields such as medical, military, aviation, robotics and manufacturing, construction, education and entertainment. It will also have a significant effect on improving the training effect of crane operators

\section{VIRTUAL REALITY APPLICATION IN TRAINING}

In order to change the status quo of the crane operator training, this paper designs and develops a bridge crane operation simulation system based on virtual reality technology. The system is developed on OSG system. It is easy to develop all types of VR system.

The system is a simulation operating system used for bridge crane operation training, skills training, safety education and practice examination. It is mainly in the following several aspects to improve or improve the bridge crane operation personnel training and assessment of the effect.

The simulated system of gantry crane is composed of several parts, including visual system, human-computer system, hardware system. See the function of these parts in Figure II.

\section{A. The use of Virtual Reality Immersion, Improve \\ Understanding of the Mechanical Structure and Working \\ Principle}

The system uses 3D virtual simulation technology to produce realistic 3D bridge crane working scenes and working conditions, as shown in Figure III. Trained person operate the bridge crane in 3D scene, with a strong sense of the scene, by using a large screen projector or a stereo imaging lens.[3]

In addition, through the system the students can also be close to the observation of the bridge crane metal structure and operating mechanism. [4]Even the invisible parts, such as the reduction of internal and so on, can be real-time observation. 
The students can directly comprehensive and study the various components, operation principle and work way of the bridge crane.

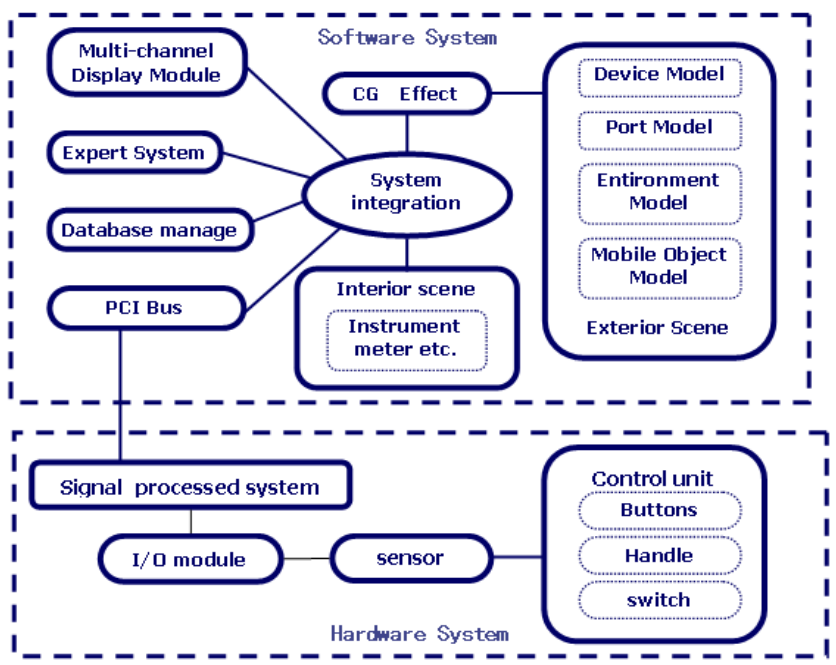

FIGURE II. MODULE OF FUNCTION

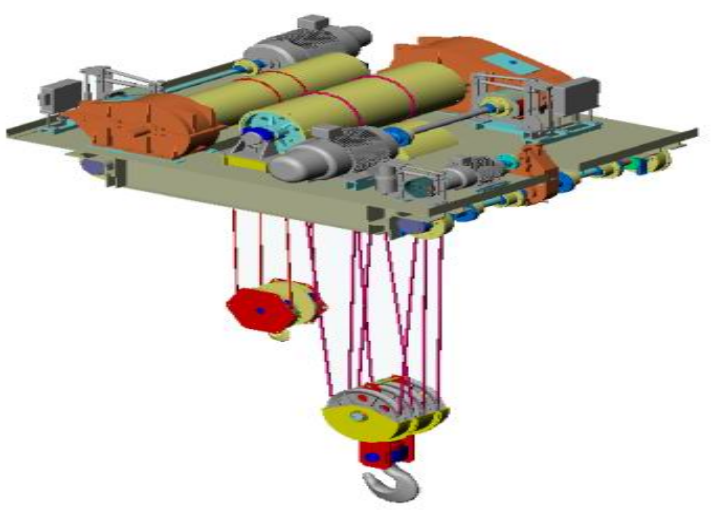

FIGURE III. TROLLEY MODEL OF BRIDGE CRANE

\section{B. Improve the Actual Operation of the Operator by Virtual Reality}

The system can be very good so that the operator can march real-time interaction in the three-dimensional scene, in the scene can run trolley, hook, all kinds of safety devices to get skills training, as shown in Figure IV. The operator can understand the basic principles and basic knowledge of the bridge crane, experience the action of the bridge crane, and feel the action mode of all kinds of safety device.

\section{Accident Reconstruction and Case Analysis}

In the operation training, trained personnel can observe and analyze their operation training through repetition functions at the scene to, especially the great errors occurred in training process, such as a car, hit obstacles, eating rail, a safety device. Use of effect is reproduced to judge and analyze the error reasons. The system is suitable for the operation of the students with no experience, and some the novice to carry out the actual operating exercises.
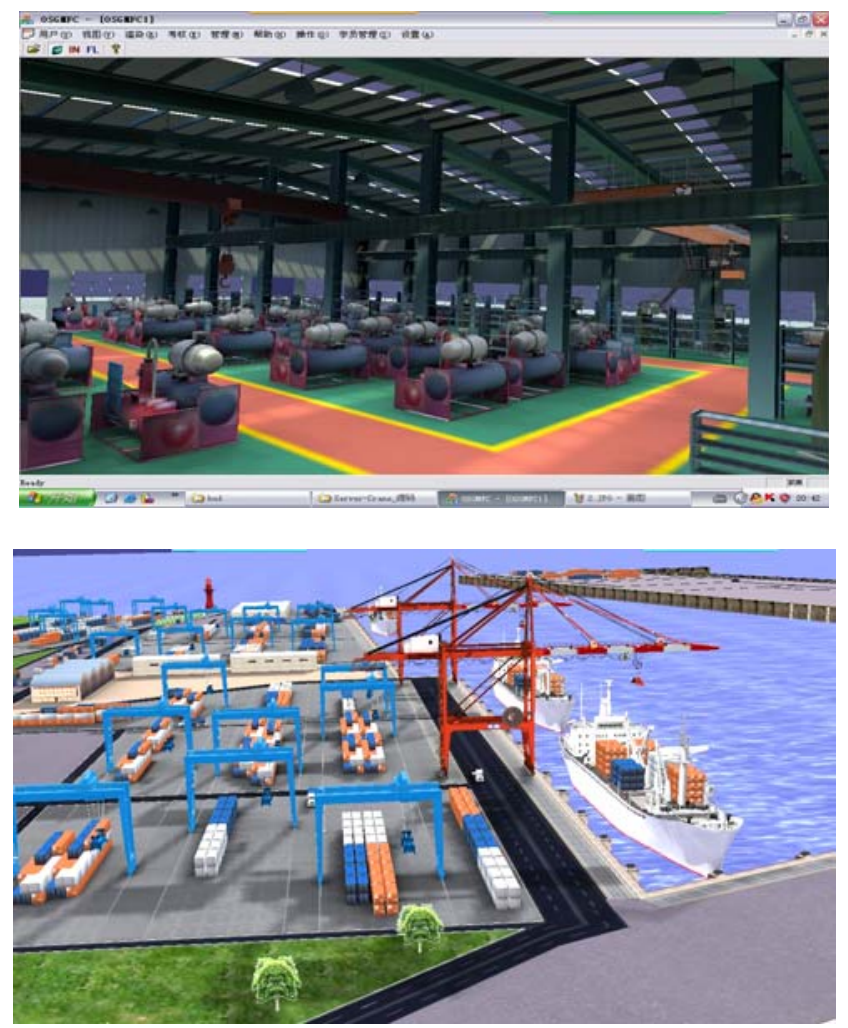

FIGURE IV. THE WORK OF THE VIRTUAL BRIDGE CRANE

\section{The Main Advantages of the System}

Compared with previous training and assessment methods, the bridge crane simulation operating system based on virtual reality technology will have a strong function, in the training, assessment; security technology has the following advantages:

\section{A. High Security}

Using the bridge crane simulation operating system can safely carry out high-speed, extreme driving and very dangerous safety experiments, which cannot be achieved in the experiment.[5]

\section{B. Good Reproducibility}

Because the bridge crane is used in the difficult and complex the state and factors, the real vehicle experiment is hard to get. And the bridge crane simulator based on virtual reality technology can conveniently carry out data acquisition, model selection and setting of the simulation environment.

\section{High Economic}

Compared with the real vehicle test, the simulator occupies a small area and consumes less energy, and it can also be more convenient to set up various experimental conditions and experimental parameters in the software environment.

\section{V.SUMMARY}

Virtual reality technology is a comprehensive technology. The basic idea is to use modern technology to create a virtual space, people can realize in this space to see, listen, move and other interactive activities, like in real environment. The user 
can enter the environment and manipulate the object and the interaction. [6]

The virtual reality is applied to the training of operator training, which is to design and realize the virtual visual concept, to realize the real scene effect, and to provide users with a variety of visual, auditory, tactile and other natural perceptive.

The bridge crane virtual training system in the actual use of the process has achieved a good effect, shortened the training cycle, reduced training costs, significantly improved the bridge crane operator training quality and efficiency

\section{REFERENCES}

[1] Shaojun Zou, Dingfang Chen and Hongliu Xu, Research and Development of Distributed Bridge Crane Training System Based on Virtual Reality, 2009 second international conference on intelligent computing technology and automation, 10-11 October 2009 Page 670-673

[2] Zhou Jian. The Analysis of Virtual Reality Technology and its Application in Teaching. Wireless Internet Technology, Wireless Internet Technology. 2015,15.

[3] Zhonghua Lu Chenlin Shen and Zhe Liu, Research on distributed multi-screen overhead crane simulator, 2008 3rd International Conference on Pervasive Computing and Applications, ICPCA08

[4] Jianguo Chen, Jianjian Ye and Dingfang Chen, Research on the Method of Visual Reality Modeling [J] Journal of Hubei University of Technology, 2005 Vol.20 No.3 P.50-51,54[ 6]

[5] Wang Xian-yuan, He Han-wu, Wu Yue-ming. The Application of Virtual Assembly Simulation and Evaluation for the Crane in Port. Equipment Manufacturing Technology, 2015.4

[6] He Chengzhong, Miao Hui, Deng Biao. Application of virtual reality simulation test system of container terminal based on numerical simulation Hoisting and Conveying Machinery. 2015,09, P 70-73. 